\title{
DE MEMORIE EN INSTRUCTIE VOOR JACOBUS COUPER

\author{
ALS HOOFD DER EXPEDITIE TEGEN SOEROPATI \\ UITGEZONDEN IN HET JAAR 1684. ${ }^{1}$
}

DOOR

E. H. B. B R A S C A M P.

Bij Resolutie van Gouverneur-Generaal en Raden van India van 16 Augustus 1684 werd Jacobus Couper aangewezen als hoofd der expeditie en krijgsmächt, die besloten was tegen Soeropati af te zenden.

Dr. F. de Haan ${ }^{2}$ merkt naar aanleiding hiervan op:

« Nergens echter in de Resoluties krijgt Couper eene instructie «daaromtrent. Alleen wordt 31 October, nadat zijne expeditie "reeds was afgeloopen en hij te Cheribon was teruggekeerd, aan "hem de last gegeven, om "voor sijn vertreck van Goulongan «aldaar en alomme in die bovenlanden soodanige ordres aan de «Javaanse Hoofden (te stellen), als nodigh sal sijn om het weder " $t$ ' samenrotten deser rebellen voor te komen en haar te destrueren »; «hij moet terugkeeren naar Batavia «nadat hy de nodige ordres "ook op Chirrebon gestelt sal hebben». Dit is het eenige wat "zou kunnen worden uitgelegd als eene officieele lastgeving om "de Preangerzaken eens voor al te regelen. Men schijnt die zaak "niet als van veel gewicht te hebben beschouwd, zoodat ook "over zijne verordeningen heel niet naar Nederland werd ge"schreven. Alleen leest men in de Afgaande Patriase Missive «30 November 1684, dat Couper vertrokken is naar de boven"landen "met ordre ook om de landsaaken alomme na vermogen "ten goeden te bestellen, zoodanigh het in der besten voegen «soude konnen geschieden, volgens seecker concept notitie over

1 Uit het Koloniaal Archief XXX. De Nrs. I-XXIX zijn of zullen worden opgenomen in het Boschbouwkundig Tijdschrift Tectona, jaargang 1917, v.v,

Priangan, deel III, $\S 495$, blz. $301 \mathrm{vv}$, 
"die dingen en Comps. belangen derwaertsover, t' onser ordre "door den Extraord". Raad Joan van Hoorn en geciteerde E. "Couper van het geheele territoir tesamengestelt en hem ter "speculatie en narigt medegegeven, als oock aan den E. Cops "op Japara gecommuniceert, om na hun bekome speculatien * daerop nader bij ons op beraden en ijets positive vastgestelt te "werden»".

De bovenstaande mededeeling van Dr. de Haan berust echter op eene vergissing. In de in het Koloniaal Archief te 's Gravenhage aanwezige copie der Resoluties van de Hooge Regeering te Batavia, leest men nl.: ${ }^{1}$

\section{«MAANDAGH DEN 28 en AUGUSTY 1684.}

«In Rade gelesen ende geresumeert zynde de Instructie door "den Heer Gouverneur-Generaal geconcipieert om den E. Jacob "Couper als hooft der expeditie en aff te gane krygsmagt tegens "Sourapatty medegegeven te werden, ende denselven tot narigt "te dienen, is deselve met de meeningen der vergadering over"eenkomende bevonden, Zulx die in het nette geschreeven synde "voorts met onse ondertekening staat becragtigt te werden".

Couper werd dus wel degelijk van eene Instructie en eene Commissie voorzien, zooals o. a. ook nog kan blijken uit het door hem den $2^{\text {en }}$ December 1684 ingediende schriftelijk rapport ${ }^{2}$, waarvan de aanhef luidt:

\section{"Hoogh Gebiedende Edle. Heeren.}

"Aangesien wy nu Edle. Hoogh Agtbaarhedens by onse gantsch "vorige advysen (:staande ons afwesen soo van Chirrebon als "uyt de bovenlanden:) gedepescheert, successief verthoont

\footnotetext{
1 Koloniaal Archief 599.

2 "SCHRIFTELIJK RAPPORT door den Commandeur ende Veltoverste Jacobus Couper opgestelt en gedaan aan d'Edle Heer Joannes Camphuys, Gouverneur Generaal en d'Edle Heeren Raden van Nederlts. India, nopende Syn Eds. Commissie in het rervolgen van den Rebelligen Sourapatty en verdere Balyse aenhangh in de bovenlanden van Prayangan en Galo, mitsgaders het bestellen van de vereyschte ordres aen de respective Gouverneurs van de Landen en voornamentl. in het wyder uytvoeren van hoogh gedagte Haar Edns. verdere bevelens raackende de Emancipatie der Chirbonse princen", voorkomende in het vijfde deel der Bataviase Inkomende Brieven, overgekomen in 1685: Koloniaal Archief 1296.

In extract is dit rapport zonder den hier vermelden aanhef weergegeven bij De Jonge, De Opkomst enz., deel VIII (V), als Bijlage XXVII op blz. 166 vv.; eveneens gedeeltelijk bij De Haan zelve (Priangan, deel 1II, blz. 306 vv).
} 
"hebben, wat van ons wesen, doen en laten geweest zij, soo « hebben wij het egter van ons gehoudens gedaght om Uw Edle. «' tselve wat ampelder in deser voegen onderdaniglyck voor oogen "te stellen.

'Zeggende aanvanckelyck, dat wy naar 't bekomen van onse - commissie, Instructie en verdere papieren daartoe gehorende, « verselt met de mondelinge gehonereerde bevelens van zijn Edht. «den Hr. Gouverneur-Generael den $7^{\text {en }}$ September met enz. enz.

Uit dit rapport blijkt reeds, dat Couper eene Instructie medegekregen heeft en eene Commissie. Beide trof ik bovendien aan in het Koloniaal Archief in het Bataviaasch Uitgaand Briefboek van $1684^{\prime}$. De Instructie luidt als volgt:

"Memorie en Instructie voor den Commandeur Jacobus COUPER als opperbevelhebber mitsgaders crygs- ende veltoversten over dese uytgesette magt te water na Cheribon ende van daar te lande nae Goelongon tot demping en verdelging van den verrader en moordadigen Balyer Soerapatty met synen aanhang, om dan wyders met het meerendeel van deselve crygsmagt oostwaart op voort te trecken na 't Hoff van den Sousouhounang ende aldaar sulx te verrigten als hem by nader af te senden memorie ofte instructie zal werden aanbevolen ende gerecommandeert.

Uyt onsen brief den 19 Mey jongstleden aan den coopman Marten Sampson en den Raadt na Cheribon geschreeven zal U Ede connen blycken, dat te dier tijt omtrent den bovengen. moordadigen verrader Sourepatty ende synen aanhang van onse meninge ende intentie $z y$ geweest en uyt een nader nae derwts. gesonden briefien onder dato 29 derselve maant, dat wy op becomene tydinge van de aankomste eeniger Engelsz. schepen in de mont van de Straat Sunda \&a. genootsaackt en te rade geworden zyn alle onse militie (uytgesondert 60 Europeen en 60 inlanders tot bewaring en besetting van onse vesting) van daar ten spoedigsten na herwaarts op te roepen endegevolgelyck den optogt na gem. Sourapatty (waartoe wy ook al de nodige provisien, oorlogsgereetschappen \&a. met het fluitschip Oosterblocker na Cheribon hadden affgeveerdigt) tot nader gelegentheyt op te schorten en uyt te stellen en nadien de donckere wolck van swaarigheyt ten opsigte van de gem. Engelsz. nu weder

1 Koloniaal Archicf 814. 
eenigermaten schynt verdwenen en overgewayt te zyn en het de tydt comt te vereysschen, dat deselve gestaackte optogt hoe eer liever voortganck neme, eens deels, omdat meergem. Sourapatty en syne trouweloosen hoop door van hier weglopende slaven en parthye andere vlugtelingen met den Pangiran Pourbaya en den moorsen priester Cheeg Joseph, die chun aldaar in de velden en bosschen hebben weten te verschuylen, hoe langer hoe stercker en magtiger wert, en ten andere om aan soodanige booswigten, mitsgaders andere hier omtrent gelegene en swervende volckeren, een exempel te statueren, waardoorse mogten worden affgeschrickt in toecomende diergelycke schelmstucken omtrent d'E. Comp. en hare onderdanen te plegen, zoo is op..... deser in de name des Heeren in rade van India goet gevonden en gearresteert daartoe uyt te setten en te gebruycken een getal van 475 Europese en 301 Inlandse soldaten, de eerste in 8 en de andere in 4 comp. verdeelt, alle gesont volck, waar mede wy gantschelyck willen verhoopen, dat; tot roem en ontsagh van 's Comps. wapenen, wat goets zal werden uytgerigt, en dewyl om sulx onder Godes zegen en bystant te effectueren, niet nodiger zy, als dat over deselve troupen worde gestelt een manhaft, cloeck en voorsigtigh crygsoverste en die deselve expeditie en 't gene hem na 't voltrecken van deselve zal werden aenbevolen ende gerecommandeert, mag werden betrouwt, zoo is na deliberatie en examinatie van saacken verstaan daartoe te gebruycken den E. Commandeur Jacobus Couper bovengenoemt, blyckende by de commissie daar van op zyn persoon verleent. En om zyn E. met raadt en daadt te adsisteren en by te wonen, is mede goetgevonden hem by te voegen de capiteyns Herman Dircksz. Wanderpoel, Willem de Ruyter en Joannis Maurits van Happel, alle mannen, die voor desen hebben doen blycken, en zoo wij vertrouwen nu weder betonen zullen, dat het haar aan geen beleyt, voorsigtigheyt en couragie en comt te gebreecken, waar benevens dan zoo veel en soodanige andere als luytenants, vaandragers \&a. in rade sullen mogen en moeten werden gebruyckt, als na gelegentheyt van tyt en saacken sal g'oordeelt worden nodig en dienstig te syn, sullende den resident tot Sirrebon den coopman Marten Sampson, die wy verstaan hebben, dat aldaar in Comps. vesting de Bescherminge verblyven en niet mede optrecken zal, rang in gem. raadt hebben tusschen de twee laastgem. capitains De Ruyter en Van Happel, 'twelck te verstaen sy van den raad; 
die op Sirrebon beleyt en gehouden zal worden, zoo voor den optogt, als nadat de magt weder aff en tot Sirribon aangekomen zal zyn. Op wat wyse ofte in hoe veel troepen verdeelt UE. zult dienen op te trecken om den vyandt met voordeel aan te tasten, te besetten en het vlugten na ontoeganckelycke bergen te beletten \&a., connen wy UE. in desen niet voorschryven, maar zullen het een en het ander aan het beleyt en oordeel van UE. en den gem. raad moeten bevolen laten, nadat het de tijd en gelegentheyt comt mede te brengen, mitsgaders den gemelten vyandt zig sal vertoonen en aanstellen, zynde onse eygentlycke intentie om tot affschrick van andere te straffen de bovengem. horibile en verraderlycke moort, die den gem. Sourapatty en de zynen aan 's Comps. volck en dienaren op Tsicalong hebben begaan en gepleegt, en dat dien volgende getragt moet werden, deselve vyanden alle bedenckelycke affbreuck te doen, jae deselve tenemaal te verdelgen en uyt te roeyen sonder ymandt te verschoonen, die tegenweer bieden ofte in de wapenen gevonden worden, en haar niet begeren gevangen te geven, tot welck laatste zy ook al moesten resolveren, eer het op een treffen aankomt, alsoo wy met dat volck alse in 't leven worden gespaart, telckens verlegen zyn, want zoo haast alse gepardonneert zyn, en maar kans sien om te vlugten, lopense weder na den vyandt, gelyck de ondervinding nog dagelyx comt te leeren, schynende het rooven en steelen en op den Javaansen boer te loopen al geheel gewent te syn, en daar by meer gemack te vinden, als selve met den landbouw en den arbeyt hunner handen de cost te winnen, hoedanigen slag wy vast stellen, dat desen Jare met het schip 'tHuys te Merwede van Sirrebon na Macassar vervoert zyn, dewelcke voor 't meerentdeel al weder sullen tragten op Java te geraacken, om aldaar hun oude leven te leyden, behalven dat'er eenige, wiens vrouwen door den Capn. Joan Ruys na herwaarts gesonden en overgebragt zyn, hier mede tersluyck sullen soecken in de stadt te comen, om met deselve haar wyven weder door te gaan, niet alleen tot nadeel van dengene, aan wien dese voor slaven zijn vercogt; maar ook van d'E Comp en de goede ingesetenen in 't gemeen, nadien se onse maniere van oorlogen kennende, veel looser als andere en daarom zoo ligt niet te agterhalen zyn, sulx dat barmhertigheyt omtrent soodanige wolven, guyten en booswigten niet oneygentl. gesegt kan worden te wesen een wreetht. tegen de schapen en soo veel onnosele menschen, als door haar suc- 
cessive worden om 't leven gebragt en daerom zeggen wy nogmaal, dat men haar in de furie niet al te mededogende moet zyn, maar met de vrouwen en kinderen sal wel wat sagter mogen werden gehandelt, om de Christen name onder dese moorse en heydense natien niet gehaat te maken. Wij willen hoopen, dat UE. den gem. schelmsen hoop soodanig sullen connen besetten, datter geen off weynig comen te ontsnappen, dog ingevalle sy het op een vlugten mogte stellen door bosschen en over bergen, daar UE. geen kans zagen (sonder veel tijdt en parthy van ons volck spillen) haar te vervolgen, dan zal sulx moeten nagelaten en tot beter gelegentheyt uytgestelt worden, alsoo het tegenwoordig niet geraden zy eenige dangereuse exploicten aan te vangen en by de hant te nemen, en sullen UE. dan ' $t z y$, dat den vyandt off verdelgt off verjaagt wort, met alle de militie weder na Sirrebon moeten afftrecken, ons van UE. verrigten met een expres snedig vaartuygh ten spoedigsten advys gevende, en dan voorts afwagtende onse nadre ordre en last, wat wyders van UE. commissie en verrigten omtrent den Sousouhounang zal zijn; onderwylen zal alles tot dien optogt gereet gemaackt, en door aff te sendene boden aan de Javaanse bevelhebbers ofte regenten van den gem. Sousouhounang daar van kennis gegeven worden, ten eynde zy ter plaatsen van haar gebiet soo veel volck tot dragers en andere behoeften besorgen ende in gereetheyt houden, als UE. uyt ervarentheyt weet, dat daar toe van noden zy en menen wij best te wesen, dat UE. hun niet en belemmert met veel van nu aftgaande Inlandse militairen, maar dat deselve off immer het meerendeel daarvan, nadat de zaken met Sourepatty sullen affgedaan zyn, mette eerste gelegentheyt weder herwaarts keeren, om soodanige redenen van hare baldadight. \&a. omtrent de Javanen, als UE. mede niet onbekent cunnen zyn, gelyck UE. dan oock om andere dog goede redenen weder tot ons sullen laten overcomen de gem. E. Captn. Wanderpoel, om alhier zyn post aan de nieuwe poort waar te nemen, alsoo wy menen dat het met de twee andere captns. wel sal connen werden affgesien. Wat ammunitie van oorlog en andere nootwendigheden voor desen met het bovengem. fluytschip Oosterblocker ten behoeve van de alsdoen voorgenomene expeditie na Sirrebon affgesonden, en aldaar nog ten principalen in wezen zyn, ende wat UE. dog daar en boven volgens eygen gedanen eysch en opstellinge ten zelven eynde medegegeven wort, sal by de nevensgaande facturen respectv. 
connen blycken, ende voor welcke goederen, opdat se niet verwaarloost maar in behoorlycke agtinge genomen werden, UE. ordre zullen moeten stellen, dat de nodige sorge wert gedragen, zynde de gene die als nu aff gaan off immer ten principalen gescheept in de gem. fluyt Oosterblocker, omdat deselve tot Sirrebon off daar omtrent een lading hout ingenomen hebbende, van daar weder herwaarts zal moeten keeren, maar de andere dry bodems, daar de militie op verdeelt is, sullen na de oost moeten voortgesonden worden, namentlyck Hellevoetsluys na Lassem ofte daaromtrent, om van daar aff te halen een ladingh zout, en hetzelve dan voorts na Sumatras Westcust te voeren; de fluyt Swanenburg na Caliwongen off Samarang, om de aldaar in voorraat leggende duygen en andere ligte houtwercken in te nemen, als zynde tot het laden van sware balcken \&a. te swack en onbequaam; sullende het jagt Rouwerswaal mede na Damack moeten voortgesonden worden, indien het tot ofte omtrent Seribon geen dienstige lading bekomen kan, zynde insgelyx een swack scheepie, dat niet te veel gevergt, nog met te swaren last beladen dient te worden.

Hoedanig de saken staan tusschen de Sousouhounan om de 3 princen gebroeders van Sirrebon, is UE. mede ten vollen bekent, sulx UE. haar op een vrundelycke en niet min ernstige wyse sullen moeten inscherpen, hoe nodig het $z y$, dat'er een uyt haar personelyck na boven opreyst om Zyn Mayesteyt tot haar eygen beste en gerustheyt zoo veel genoegen te geven, als wy menen, dat betamelyck is, en zy oock schuldig zyn, 't welk onses eragtens als nu met ende benevens UE. seer bequamelyck en ten opsigte van hare voorgewende vreese met de minste becommering zoude connen geschieden, gelyck zy selve wel zullen connen begrypen, en soude wy geerne ten spoedigsten berigt wesen, wat dienaangaande van hare intentie mogte wesen, om onse aff te zenden brief aan den gem. Sousouhounang daar na wat te reguleren; gaande het briefien, dat wy alsnu aan de voorm. dry princen schryven, hier bygevoegt, gelyck mede de copie om UE. daer van tot narigt en speculatie van te connen dienen.

Ende zoo mede seker berigt dat door den E. Joan Van Hoorn met UE. en den Commandeur Hartsinck is opgestelt, ten reguarde van de landtstreecke tusschen Batavia en Sirrebon en op onse ordre te samen gebragt in opsigt van diverse versoeckschriften, die ons van dees en gene Javaanse hoofden waren voorgekomen, 
'twelck in onse vergaderinge $z y$ geresumeert en gemeent voort meerendeel soodanig gereguleert zoude dienen te werden, als het daar toe te brengen zal wesen, daar na UE. dan by provisie het zoo wat moeten tragten te schicken, insonderheyt in opsigt van de landen van Carwang tot Pamanoekan toe, en ook verders zoo als daar by wert aangehaalt, en weswegen inmiddens als UE. in de bovenlanden van Chirrebon en daar in loco zijt, UE. nader speculatien en consideratien zullen affwagten, om dan verder het noodige in te connen disponeren en te ordonneren. Hier mede \&a.

Onderstont. UE. goede vrunden. Was geteeckent. J. Camphuys, A. Hurt, W. van Outhoorn, Mtn. Pit en J. van Hoorn. Ter zyden. Batavia int Casteel den 5 September 1684.

lager stont. $\mathrm{Na}$ het sluyten deses ons onverwagt de tydinge toegecomen wesende, dat het jagt 't Huys te Cleve op $31 \mathrm{Aug}^{\circ}$ na Palëmbang affgeseylt den...... deser op eene der Duysent Eylanden, Godt betert het, is verongeluckt, zoo hebben ons tot affhaal van den gereeden peper van daar eenigermaten verlegen bevonden, en oversulx moeten resolveren de fluyt Oosterblocker (met UE. gedestineert) hier weder aan te houden, om ten spoedigsten mettet benodigde naar voors. Palembang voort te gaan en oversulcx de inlandse militie en ammonitien als anders uyt deselve ftuyt aanstonts op het schip Den Hollandsen Thuyn te doen overgeven, waar met wij hoopen UE. het selve morgen avont te laten volgen.

En vermits 'er boven Oosterblocker nog al meer scheepsruymte tot affhaal des pepers comt te requireeren, zoo zal UE. 't jagt Rouwerswaal na syn verschyninge op Chirrebon ten eersten als het maar gemist con werden, direct weder na herwaarts laten retourneren, om hier nader gevisiteert te werden, off het tottet overhalen van nog een peperlast, 'tzy van Palembang off van Bantam bequaam zal zyn, dewyle datter mits desselfs sobere gestalte ligtel. geen hout off eenige andere ladinge meer in te vertrouwen schynt te wesen, zoo als ons daar by nader onderrigtinge nu even $z y$ te vooren gecomen.

Onderstond. Ter ordonnantie van haar ho. Eds. den Gouverneur Generael en de raden van India. Was getekent. Abraham van Riebeecq, Sects. Ter zyden. Batavia int Casteel den $6^{\text {e }}$ September 1684.»

Den Haag, Juni 1918. 